\title{
Guilleermo
}

de Delsham

Artículo original $\odot$ Acceso abierto

\section{Medios de comunicación y accionar político: apuntes para una fenomenología de la mediocracia en Colombia}

\author{
Media and political procedure: notes for a phenomenology \\ of the mediacracy in Colombia
}

\author{
Juan Diego Hernández Albarracín.i (i) (arlos Lasso Urbano.i \\ Marc Pallarés Piquer.i. (i) 을 Magali Alba Niño. ${ }^{\mathrm{i}}$ \\ i. Universidad Simón Bolívar; Cúcuta; Colombia. \\ ii. Universidad Jaime I.; Castellón de la Plana; España.
}

Correspondencia. Juan Diego Hernández Albarracín

Email: j.hernandez@unisimonbolivar. edu.co

Recibido: $26 / 09 / 2019$

Revisado: 28/09/2020

Aceptado: 02/11/2020

Citar así: Hernández Albarracín, Juan Diego; Lasso Urbano, Carlos; Pallarés Piquer, Marc; Alba Niño, Magali. (2021). Medios de comunicación y accionar político: apuntes para una fenomenología de la mediocracia en Colombia. Revista Guillermo de Ockham. 19(1), 95-110. https://doi.org/10.21500/22563202.4310

Copyright: ( $) 2021$. Universidad de San Buenaventura, Cali. La Revista Guillermo de Ockham proporciona acceso abierto a todo su contenido bajo los términos de la licencia Creative Commons AttributionNonCommercial-NoDerivatives 4.0 International (CC BY-NC-ND 4.0).

Conflicto de intereses. Los autores han declarado que no hay conflicto de intereses.

Disponibilidad de datos. Todos los datos relevantes están en el artículo. Para mayor información contactar al autor de correspondencia.

Fondos. Ninguno. Esta investigación no recibió ninguna subvención específica de agencias de financiamiento de los sectores público, comercial o sin fines de lucro.

Descargo de responsabilidad. El contenido de este artículo es responsabilidad exclusiva de los autores y no representa una opinión oficial de sus instituciones ni de la Revista Guillermo de Ockham.

\section{Resumen}

Se pretende en este escrito, hacer una crítica a las formas hegemónicas de comunicación que intervienen como actores políticos en Colombia, para configurar posiciones de sujeto afines a los intereses del poder de los que hoy forman parte. Por lo anterior, el trabajo se estructura de la siguiente manera. Primero, se hace una crítica al capitalismo cultural a partir de la lectura deleuziana y su articulación con las empresas informativas. Segundo, revisar la experiencia del conflicto armado colombiano (CAC) vista a partir de las matrices de verdad construidas por los medios de comunicación de masas para colonizar los mundos de vida y se finaliza con la interpretación del concepto de mediocracia, de Danny Schechter, que convierte el medio en actor político servil a las sociedades de control. Así, proponemos un recorrido para aportar a la revisión crítica del poder mediático y su papel determinante en los acontecimientos políticos en Colombia.

Palabras clave: mediocracia, comunicación, acto de creación, política, poder.

\section{Abstract}

It is intended to make a criticism of the hegemonic forms of communication that intervene as political actors in Colombia in order to constitute subject positions related to the interests of power that are part of it. Hence the work is structured: first, to make a critique of the cultural capitalism from the Deleuzian reading and its articulation with information companies; secondly, review the experience of the Colombian armed conflict (CAC) seen from the truth matrices constructed by the mass media to colonize the worlds of life, to finalize with the interpretation of the concept of Mediacracy from Danny Schechter, that converts the medium in political actor subservient to control societies. Thus, we propose a look over to contribute to the critical review of media power and its determining role in political events in Colombia.

Keywords: mediacracy, communication, act of creation, politics, power. 


\section{Introducción}

Se abren discusiones al respecto de contemplar una diferenciación crítica entre la comunicación como proceso auténtico de expresión humana en los planos ético, histórico y político y los medios de comunicación de masas como instancias instrumentales de vinculación informativa, que se orientan hegemónicamente a privilegiar intereses privados que acentúan el gobierno sobre los otros.

Por esto, recurrimos a diversificar el acontecimiento de la comunicación por encima de su fenomeneidad hegemónica, desde la facultad del acto de creación, ${ }^{1}$ partiendo de una dimensión del diálogo enfocado en "expresar diferencias, distancias, crear perspectivas incompatibles, distinciones, no tomar acuerdos. La función de la comunicación es relacional antes que referencial" (Pardo, 2014, p. 154), debido a que no parte de una necesidad transmisora en positivo, sino de una relación conflictual, antagónica, que busca desatar las diferencias para otorgarles existencia.

De ahí que la comunicación redefina el sentido de las relaciones entre subjetividades al posicionar un acto de creación a la configuración del espacio cultural, ya no como cultivo arquetípico de una tradición quietiva, sino en la excitación máxima de formas de vida necesitadas de presencia fáctica, lo que implica aperturas subalternas que deshagan las fundamentaciones de las relaciones de poder hegemónicas que vuelven monológica la idea de comunicación y por ello también las maneras de la cultura.

Las estrategias adoptadas en la producción de comunicación de masas han cumplido a cabalidad las funciones asignadas por parte de las instituciones públicas y privadas, con lo cual los comportamientos sociopolíticos impuestos tienen impacto en la concepción y visión de mundo de los sujetos, en las estructuras expresivas y en la narración de los relatos, impacto que se materializa en el conjunto de la sociedad. En suma, los efectos de la comunicación burguesa sobre la conciencia resultan bastante significativos para los intereses de la industria cultural, al incidir en la conducta de los sujetos. De hecho, la mayoría de los receptores hoy continúa siendo una masa dispersa que, aunque tiene la posibilidad de producir mensajes, se aboca al ocio y a la evasión, lo cual "quiere decir que (...) la información sigue primando sobre la comunicación y que una abrumadora mayoría de seres humanos posee mentalidad que emana desde los grandes emisores, sobre los que ejerce una interacción generalmente epidérmica y hasta cómplice”. (Reig, 2017, p. 23)

De ahí que se haga necesario que la concepción comunicativa que asumamos orbite posiciones contrahegemónicas en el sentido de asumir una dinámica alternativa que a partir de la facticidad política permita enfrentar críticamente las estructuras de una representación mediática que favorece el fetichismo del poder, ${ }^{2}$ desnudando la praxis política de su aplicación comunitaria como sentido de solidaridad, criticidad y alteridad.

1. Nos interesa pensar la creación en acto como una forma de materializar una comunicación distinta a las relaciones objetivadas de las sociedades de control que son condicionadas a partir de los medios de comunicación de masas. Por el contrario, es indispensable asumir una singularidad comunicativa habitante de territorios de pensamiento-expresión que operen más cerca del arte como resistencia que a las facultades de la comunicación informativa entendida como ordenación de la palabra. Así, "el acto de la palabra es un acto de resistencia. Desde Moisés hasta el último Kafka, hasta Bach. Recuerden, el acto de la palabra en Bach, ¿qué es? Es su música, es su música que es acto de resistencia. Acto de resistencia ¿̨contra qué? No es el acto de resistencia abstracto, es acto de resistencia y de lucha activa contra la repartición de lo sagrado y lo profano. Y este acto de resistencia en la música culmina con un grito. Como también hay un grito en Woyzek, hay un grito de Bach: "afuera, afuera, no quiero verlos". Eso es el acto de resistencia. A partir de esto me parece que el acto de resistencia tiene dos caras: es humano y es también el acto del arte" (Deleuze, 2012, p. 16).

2. Tiene que ver con la apropiación del poder delegado (potestas), de las condiciones originarias que lo sustentan (potentia), esto es como afirma Dussel (1996) en Filosofia de la liberación, del "desplazamiento de un ejercicio estrictamente por delegación como poder obediencial, a un ejercicio autocentrado del representante que se afirma como sede última del poder constituye el origen del proceso corruptivo originario que denominaremos "fetichismo del poder" (p. 326). Asunto que se expresa, por ejemplo, cuando "el actor político (los miembros de la comunidad política, sea ciudadano representante) cree poder afirmar a su propia subjetividad a la institución en la que cumple alguna función (de algo que pueda denominarse "funcionario"), sea presidente, diputado, juez, gobernador, militar, policía como la sede o la fuente del poder político”. (Dussel, 2006, p. 13) 
A partir de las filosofías críticas latinoamericanas y de gran parte de la tradición antropológica (simbólica) de la escuela de Chicago, comprendemos que las formas del pensamiento son siempre sociales y públicas (Geertz, 2003). Estas se entienden como el "modo en que el sujeto adopta como posición intersubjetiva en un campo con otros" (Dussel, 2006, p. 20), por lo que comunicar siempre tendrá que ser un evento éticopolítico en el sentido de configurar, discutir o reproducir los mecanismos de control de la conducta que presencia devenir en la cultura.

De esta manera, declaramos que el medio de comunicación de masas ostenta dinámicas reaccionarias al ser una potencia política que masifica, razón por la cual uniformiza la diversidad cultural. Así, la libertad de información se une a la libertad de empresa y de comercio para adquirir una vocación imperial (Martín-Barbero, 2010), subordinando así toda interpretación a sus mecanismos informativos, los cuales "rolifican a los actores y por tanto, quienes les enajenan, cuando reducen el quien del sujeto a lo que el sujeto representa en el relato. Pero sobre todo poseen el poder del silencio". (Martín-Serrano, 1993, p. 327)

Con base en el hecho de que para estudiar la influencia de los medios se debe profundizar en el entorno empírico en el que se produce esta influencia, es el objetivo de este trabajo hacer una crítica a las formas hegemónicas de comunicación que intervienen como actores políticos en Colombia para configurar posiciones de sujeto afines a los intereses de poder de los que hoy son parte. Así, la hipótesis de partida es que los medios refuerzan vías de percepción y de comunicación que en el contexto colombiano introducirán unos estilos de vida y unas construcciones de realidades sociales, culturales y políticas (hegemónicas) predeterminadas. Para estudiarlo, nos centraremos en organizar una interpretación a partir de la comunicación como acto de creación a los medios de comunicación de masas como potenciadores de las sociedades de control, ${ }^{3}$ y propondremos un aporte substancial en los sentidos reformadores del liberalismo y sus aparatos ideológicos que condicionan cualquier lectura crítica a los grandes metarrelatos de la cultura, la historia o la política, para organizar procesos donde lo masivo como objeto interviene en la comunicación para

(...) designar únicamente los medios de homogenización y control de las masas. Y de mediadores (...) entre el Estado y las masas, entre lo rural y urbano, entre las tradiciones y la modernidad, los medios tenderán cada día más a constituirse en el lugar de la simulación y la desactivación de esas relaciones. (Barbero, 2010, p. 208)

De ahí la urgencia por reavivar ontológicamente las formas auténticas de comunicación, organizadas políticamente desde espacios utópicos adversos a "la dominación de la racionalidad objetiva y la globalización del mercado vistas desde el poder colonizado; y, a su vez, es liberadora de formas sensibles para la experiencia deseante y pensar el mundo a partir de otro modo de ser". (Márquez-Fernández, 2018, p. 119)

Así pues, la razón utópica como dimensión ético-política ${ }^{4}$ de la comunicación, instaura la complejidad poética de la intersubjetividad para extrapolar el transmisionismo

3. Esta es la expresión foucaultina para describir el estado de dominación orquestado por el capitalismo cultural a raíz de su mutación del régimen fabril al régimen empresarial. "Esto significa que hoy en día las relaciones de dominio no se asientan sobre instituciones de poder como la fábrica, el hospital, la escuela y el cuartel general, sino que tienen un modus operandi completamente diferentes. Los dispositivos hegemónicos de poder no funcionan ya de una manera seriada y cuadricular, delimitando tareas y funciones para producir subjetividades normalizadas. La crisis generalizada de las instituciones de encierro ha mostrado que en la actualidad no es suficiente, y ni siquiera necesario, encerrar los cuerpos para neutralizar su multiplicidad, sino que tal neutralización ocurre al aire libre" (Castro-Gómez, 2015, p. 214).

4. Lo ético y lo político no son dimensiones aisladas. La primera es la reflexión constante sobre los valores que orientan la vida de los seres humanos, los cuales pueden ser pensados desde lo singular de un sujeto o desde lo universal del ser social; la dimensión política implica entender que desde los procesos de socialización y de reproducción social en la vida cotidiana, se realiza una forma de ser de la realidad, la política surge de la relación que se presenta entre los hombres como sí, es la acción y movimiento en el tiempo, el proceso en donde los 
masificador por la expresividad singular y el flujo informativo de verdad por la crítica y el autocuidado en la relación cultural, vista ya no como entretejido de dominación para el fortalecimiento de las sociedades de control, sino como experiencia singular que busca en los otros la organización plural de las demandas para el gobierno de sí mismos.

En consecuencia, se pretende, primero, hacer una aproximación crítica al capitalismo cultural a partir de la lectura deleuziana y su articulación con las empresas informativas; segundo, revisar la experiencia del conflicto armado colombiano vista a partir de las matrices de verdad construidas por el medio de comunicación de masas para colonizar los mundos de vida, para finalizar con la interpretación del concepto de mediocracia, de Schechter, que convierte al medio en actor político servil a las sociedades de control.

\section{Capitalismo y medios de comunicación de masas}

En una sociedad estructurada con base en los medios de comunicación de masas, la presencia de mensajes que se sitúan fuera de ellos se reduce a las redes interpersonales, lo que implica que a menudo se alejen de la mente colectiva. De esta manera, los medios de comunicación de masas presentan "una suerte de tecnificación de los procesos de comunicación" (Narváez, 2013, p. 87), es decir, son instrumentos, aparatos técnicos que permiten transmitir mensajes y aparecen con importancia determinante en el marco del desarrollo del capitalismo cultural "en el que las mercancías ya no son adquiridas en función a su utilidad, sino para gozar de la experiencia de su consumo (en tanto que llenan nuestra vida de significado) (Castro-Gómez, 2015, p. 14). Así, se relaciona su hegemonía con la multiplicación de las plataformas informativas a partir de internet y la transformación del mercado, puesto que se van a convertir en estrategia de acumulación y promoción del capital financiero que reproduce formas de pensamiento y acción que colonizan los mundos de vida (al ofrecer interpretaciones prefacturadas y fáciles de digerir desde el ordenamiento de la palabra para convertirla en mercancía informativa).

En esa medida, los medios desempeñan un papel importante no solamente en las relaciones de producción, sino también en la superestructura política e ideológica provenientes de las élites de poder, puesto que son partícipes de la narrativa de los relacionamientos que le otorgan cierto dramatismo a la hora de organizar las enunciaciones, trazar límites y asignar las posiciones convenientes al sujeto respecto a la generación de

(...) esas "ilusiones necesarias", en expresión de Reinhold Niebuhr, que mantienen el espejismo de la democracia. (...) los medios de comunicación fijan un debate público que excluye sistemáticamente todo lo que se salga del consenso institucional de las élites; por ejemplo, excluyen todo cuestionamiento de las intenciones "democráticas" estadounidenses. Puede discutirse si la acción X ha sido llevada a cabo con mayor o menor acierto, pero nunca se pondrá en tela de juicio la bondad de la acción X. Más sutil que un sistema de censura totalitaria, este aparato doctrinal-propagandístico persigue ante todo la aquiescencia irracional a las políticas del Poder, en el marco de un espectro ideológico limitado por el consenso de las élites poderosas, al tiempo que se fomenta un debate táctico en su interior. (Pineda, 2001, p. 198)

Lo que significa que los medios forman parte del conjunto de relaciones de poder representados en las prácticas de gobierno (gubernamentalidad) que presentan desde el siglo XVII un funcionamiento del Estado en estrecha relación con la forma de gobernar los sujetos y ordenar las cosas (Foucault, 2013) para determinar prácticas, valoraciones y actitudes en la interacción del sujeto consigo mismo y con el mundo de los otros. En

individuos y, por tanto, la forma de la sociedad, definirán las esferas a ocupar por la misma, lo político está determinado por una reflexión ética, y la ética se realiza en lo político, de manera que la reflexión ética "no tiene por objeto responder a sus necesidades inmediatas, sino sistematizar la crítica de la vida cotidiana, presupuesto para una organización de la misma, más allá de las necesidades orientadas exclusivamente al "yo", ampliando las posibilidades de realización de los individuos como individualidades libres y conscientes” (Barroco, 2004, p. 73). 
consecuencia, "las mismas condiciones que procuran la máxima efectividad a los medios de comunicación de masas funcionan en pos del mantenimiento de las estructuras sociales y culturales existentes". (Lazarsfeld y Merton, 1985, p. 49)

Es, precisamente, aquella dinámica de la gubernamentalidad la que coloniza las relaciones del sujeto consigo mismo y lo arrojan a una postura inauténtica en la cual prima la espectacularidad publicitaria del $\mathrm{Uno}^{5}$ (Das man) que pasa las relaciones entre los mundos de vida.

Por el cedazo de la industria cultural. La vieja esperanza del espectador cinematográfico, para quien la calle parece la continuación del espectáculo que acaba de dejar, debido a que este quiere, precisamente, reproducir con exactitud el mundo perceptivo de todos los días, se ha convertido en el criterio de la producción (Adorno y Horkheimer, 1988, p. 4).

Vista así, la industria cultural como constituyente del medio comunicativo de masas, aparece relacionado al capitalismo como flujo integrador de las relaciones subjetivas, debido a que la capacidad esquizofrénica vista a partir de la potencia de recuperación ${ }^{6}$ de este discurso imperante, es capaz de engullir cualquier posición que se le presente. En tal sentido, la cultura como industria, se le aparece como un mecanismo atractivo que le permitirá conducir la conducta mientras los sujetos la pasan desapercibida a causa de dinámicas normalizadas provenientes de las relaciones de poder que sustentan la continuidad del mundo moderno/colonial "garantizada por la producción de sujetos que, aunque forman parte del lado oprimido de la diferencia colonial, piensan y actúan como los sujetos de las posiciones dominantes". (Castro-Gómez y Grosfoguel, 2007, p. 3)

Es, precisamente, tal condición psicológica la que permitirá discutir el papel mediático en la consolidación de un aparato económico y político hegemónico que reproduce formas de verdad a partir del aspecto liberal y objetivo con el que se ha investido a partir de operaciones de poder que permitieron su origen, creando así un sujeto alternativo que potencia las dinámicas de un multiculturalismo liberal interviniente como el mejor aliado del capitalismo global (Castro-Gómez, 2015), para la producción de subjetividad anclada en el divertimento y la entretención que lo aparta de sí, debido a una experiencia del puro presente que:

Ha reemplazado a las expectativas del futuro histórico y el hedonismo a las militancias políticas; la fiebre del confort ha sustituido a las pasiones nacionalistas y las diversiones a la revolución. Apoyado en la nueva religión de la incesante mejora de las condiciones de vida, el vivir mejor se ha convertido en una pasión de masas, en el objetivo supremo de las sociedades democráticas. "Pocos fenómenos han conseguido modificar tan profundamente los estilos de vida y los gustos, las aspiraciones y las conductas de tantas personas en tan poco tiempo". (Lipovetsky, 2007, p. 7)

Es a partir del vínculo entre capitalismo, subjetividad y medios de comunicación de masas que observaremos las fenomenologías de lo espectacular-noticioso a raíz de los escenarios abiertos por el conflicto interno armado colombiano, para desentrañar la trama

5. Concepto heideggeriano que explica la cooptación del sujeto por el terreno de las habladurías, la curiosidad y la ambigüedad, categorías que constituyen la caída (verfallen) en la cotidianidad. En razón de esto se pierde toda decisión autónoma para relacionarse consigo mismo y el mundo, disolviendo al dasein propio en el modo de ser de los otros, y esto hasta tal punto, que los otros desaparecen aún más en cuanto distinguibles y explícitos. Sin llamar la atención y sin que se pueda constatar, el Uno despliega una auténtica dictadura. Gozamos y nos divertimos como se goza; leemos, vemos y juzgamos sobre literatura y arte como se ve y juzga; pero también nos apartamos del montón como se debe hacer; encontramos irritante lo que se debe encontrar irritante. El Uno que no es nadie determinado y que son todos (pero no como la suma de ellos), prescribe el modo de ser de la cotidianidad. (Heidegger, 2009, p. 145)

6. La potencia de recuperación es un concepto fundamental para entender el funcionamiento de la máquina capitalista. La forma de actuación de este fundamento tiene que ver con la capacidad que tiene el capitalismo para permitirse absorber la contradicción, esto es, elementos que podrían rupturar o afectar su funcionamiento. Por esto, "cada vez que algo parece escapársele, pasar por debajo de esos símil-códigos, vuelve a taponar todo, añade un axioma más y la máquina vuelve a partir”. (Deleuze y Guattari, 2015, p. 20) 
que convierte al medio en otro actor político, con la clara diferencia de que su accionar emerge investido por una historicidad liberal anclada en la mismidad de los Estadosnación, adoleciendo así, de un contrapeso que lo sitúe en alguna orilla identificable de la comunicación política, debido a que "no circula un poder que disciplina, sino un poder que seduce” (Valencia, 2012 p. 160), condición que lo hace más complejo a la hora de valorar sus prácticas y por supuesto, organizar las resistencias.

\section{Anotaciones de la influencia mediática sobre la experiencia del conflicto armado colombiano}

En los más de cincuenta ańos de conflicto armado padecidos en Colombia según el Centro Nacional De Memoria Histórica, solo hasta el momento se empiezan a esclarecer las "dimensiones de su propia tragedia. Aunque sin duda la mayoría de nuestros compatriotas se sienten habitualmente interpelados por diferentes manifestaciones (...), pocos tienen una conciencia clara de sus alcances, impactos y mecanismos de reproducción" (Centro Nacional de Memoria Histórica, 2013, p. 13). De esta manera, la influencia mediática ha sido determinante para crear las matrices de verdad que la subjetividad colombiana conserva hasta hoy.

De ahí que el lenguaje de la guerra fuese aprendido y legitimado a partir de lo que escuchan en la radio, leen en los periódicos u observan en las pantallas de sus televisores, y en esa medida "sus contenidos comerciales pueden influir directamente en la manera como la ciudadanía y los distintos actores construyen su propia perspectiva del conflicto y a perpetuar condiciones culturales estructurales que alimentan la continuidad de la violencia en todo orden" (Cárdenas, 2015, p. 42). Por lo que la libertad de opinión adquiere un matiz oscuro al no proceder del ejercicio de la singularidad, sino de una matriz de poder construida para objetivar al sujeto que normaliza su relación con la violencia. ${ }^{7}$ Cuestión por la cual el expresidente de Ecuador Rafael Correa refiere lo siguiente:

Cuando las élites latinoamericanas afirman que no existe libertad de prensa es porque sus medios de comunicación no tienen libertad para manipular la verdad o porque nos atrevemos a contestarles, a disputar su hegemonía, a desenmascarar sus mentiras. Cabría preguntarse si una sociedad es verdaderamente libre cuando el derecho a la información y a la propia comunicación social está en manos de privados con fines de lucro. Y aunque este es un problema planetario, en Latinoamérica dados los monopolios de medio, su propiedad familiar, sus serias deficiencias éticas y profesionales y su descarado involucramiento en política, el problema es mucho más grave. Debemos coincidir en que la buena prensa es vital para la democracia, pero

7. Precisamente, esta forma de normalizar la violencia por la subjetividad colombiana, es magistralmente narrada por el escritor Juan Gabriel Vásquez en El ruido de las cosas al caer, una novela que acierta en retratar no únicamente la dimensión de la violencia como una impronta cultural en los años 80 y 90 , sino la producción de subjetividad que iba a derivar en las practicas violentas del siglo XXI (agudización de las masacres, falsos positivos, alianzas estratégicas entre el Estado y la insurgencia etc.) donde la muerte era un espectáculo, pero también, un asunto cotidiano. Así, mientras algunas personas juegan billar y escuchan el televisor, el personaje principal relata que acaban de matar al candidato conservador Álvaro Gómez: "Nadie preguntó por qué lo habían matado, ni quién, porque esas preguntas habían dejado de tener sentido en mi ciudad, o se hacía de manera retórica, sin esperar respuesta, como única reacción ante la nueva cachetada. No lo pensé en ese momento, pero esos crímenes (magnicidio los llamaba la prensa: yo aprendí muy pronto el significado de esa palabrita) habían vertebrado mi vida o lo puntuaban como las visitas impredecibles de un pariente lejano. Yo tenía catorce ańos en esa tarde de 1984 en que Pablo Escobar mató o mandó a matar a si perseguidor más ilustre, el ministro de justicia Rodrigo Lara Bonilla (dos sicarios en moto en la curva de la 172. Tenía dieciséis cuando Escobar mató mandó a matar a Guillermo Cano, director del diario El Espectador (el asesino le metió ocho tiros en el pecho), tenía diecinueve y ya era un adulto, aunque no había votado todavía, cuando murió Luis Carlos Galán, candidato a la presidencia, cuyo asesinato fue distinto o es distinto en nuestro imaginario porque se vio en televisión: la manifestación que vitoreaba a Galán, luego las ráfagas de metralleta, luego el cuerpo desplomándose sobre la tarima de madera, cayendo sin ruido o su ruido oculto por el bullicio del tumulto y por los primeros gritos (....) de manera que todos los billaristas lamentamos el crimen con la resignación que ya era una suerte de idiosincrasia nacional, el legado que nos dejaba nuestro tiempo, y luego volvimos a nuestros chicos respectivos". (Vásquez, 2017, pp. $18,19)$ 
una mala prensa es mortal para esa misma democracia y la prensa latinoamericana es mala, muy mala. (Alexánder Ramírez, 2016, 0:13-1:32)

Vistos así, no desde el horizonte ideal del liberalismo, sino bajo las actuales condiciones de revisión crítica, los medios de comunicación están "destinados a instrumentalizar la libertad de opinión” (García Nossa, 2013, p. 157), esto es, como afirma el expresidente Correa, desde la invención de la imprenta, "la tan cacareada libertad de prensa es la voluntad del dueño de la imprenta, (...) no se dan cuenta que están proveyendo un derecho, no una mercancía” (Rafael Correa, 2017), por lo que asumimos que es el altoparlante de los sectores económicos que hacen experiencia de toda la esquizofrenia de un capitalismo que tiene al igual que Jano "sus dos bocas hablando el lenguaje del absolutismo y la libertad”. (De Sousa, 2003, p. 141)

Precisamente, tales dueños de imprenta que invocan la libertad mientras tienden redes de manipulación, son un reducida élite en Colombia representada estratégicamente por la organización Luis Carlos Sarmiento Angulo (dueña del periódico El Tiempo, canal City TV, periódico $A D N$, el cual circula gratuitamente), la organización Ardila Lulle, (propietaria de RCN Radio y Televisión, canal de noticias NTN 24, Win Sports, emisoras como la FM, La Mega, Radio Uno, entre otras), el Grupo Empresarial Santo Domingo (dueño de Caracol TV, periódico El Espectador, la emisora Blu Radio), el Grupo Prisa (propietario de Caracol Radio), Fundación Semana, de Felipe López Caballero (quien es hijo del expresidente Alfonso López Michelsen), propietario de la revista Semana, cedida por mitad al Grupo Gilinsky en 2018, dueño, entre otras cosas, del banco Sudameris. Se trata de la tónica general, puesto que a nivel mundial se vienen conformando macrocorporaciones que más que competir, colaboran y establecen redes de intereses que terminan condicionando la información que emiten.

Se combinan así, el negocio de la comunicación, infraestructura, fondos pensionales y bancarios para redundar en el posicionamiento de una única visión de país solicitaría del capital financiero ${ }^{8}$ para sustentar un sólido ejercicio del poder. De ahí que sean diversas las estrategias que a diario utilizan para conseguir los fines y disfrazar de objetividad la propaganda informativa, entre las que se cuentan "la desinformación, imágenes en negativo intermitentes, técnicas de inducción del temor y el estrés, sugestión cuasi hipnótica, repetición excesiva y falsificación e invenciones”. (Remsseler, en Britto García, 2005, p. 148)

Por tanto, es indispensable abrir la experiencia comunicativa más allá de los regímenes de dominación informativa del medio de masas, en el que la libertad de opinión supere el monopolio y se abra a la utopía para generar espacios plurales fundados sobre bases éticas que decolonicen ${ }^{9}$ las matrices de manipulación y censura hacia un dimensión de lo político, que alcance categorialmente una segunda emancipación desde la alteridad, solidaridad y liberación (Dussel, 2006), bases fundamentales de una práctica comunicativa como acto de creación que desterritorialice las dinámicas homogéneas de veridicción y presente el acontecimiento de la singularidad como dimensión determinante de una opinión pública no colonizada, para fundar mediaciones comunicativas sobre la base del

8. Para ampliar la discusión sobre la concentración de medios en Colombia, se recomienda revisar el estudio realizado por la Federación Colombiana de Periodistas (Fecolper) y Reporteros sin Fronteras, quienes muestran la concentración mediática, la cual se ubica principalmente en los tres grupos económicos más poderosos del país. http://www.monitoreodemedios.co./.

9. Importante profundizar la tesis 20 de Dussel sobre la factibilidad política. En razón de esto, se propone superar los caminos de la pretensión del ordenamiento democrático burgués a la luz de la proclamación revolucionaria en Francia, por un nuevo marco de comprensión que habilite praxis de liberación que no exalten monológicamente los privilegios de la élite, dueña entre otras cosas de medios de producción y comunicación, de ahí que "ahora no nos referimos a la libertad, sino a la liberación como proceso, como negación de un punto de partida, como una tensión hacia el punto de llegada. Unido a los otros postulados de la revolución burguesa que se enunciaban con la proclamación de "igualdad, fraternidad, Libertad!", debemos transformarlos en la rebelión de los pueblos oprimidos y excluidos de la periferia en sus luchas por la Segunda Emancipación”. (Dussel, 2006, p. 158) 
contrapoder y no de la propaganda, lo cual expresa bien el periodista Daniel Coronel ${ }^{10}$ al respecto de la discusión contemporánea entre periodismo y poder:

Hay algo que es grave y transversal en todos estos gobiernos y es la connivencia de los medios con el poder, lo cual es grave porque es muy importante que el lector, televidente o usuario de internet, sepa que quien está al otro lado está buscando la verdad y no la conveniencia de quien tiene el poder (...) esto es el reflejo de algo que ha venido pasando de manera natural en Colombia y que se asume de manera normal, por las tantas veces que ha pasado y es que se negocie el titular con el ministro o con el presidente. (...) Por esto la ciudadanía debe estar atenta, pues no es un servicio público aceptable buscar información y encontrar propaganda. (Falsos positivos, New York Times, columnistas de la revista Semana, 2019)

Es la naturaleza del contrapoder lo que ubica la comunicación como acto de creación en la necesidad por mediar la práctica informativa. Lo que se ha demostrado hasta aquí, es la connivencia entre el medio de masas y la naturaleza del poder en Colombia, asunto que no es una característica singular de alguna postura gubernamental, sino el sentido común de la disposición informativa del sistema-mundo cooptado por los poderes económicos, pues "uno de los graves problemas que tiene el periodismo colombiano es que está totalmente sujeto a lo que digan y ordenen los poderes económicos (...) los dueños del poder, los verdaderos dueños del poder", como afirma María Jimena Duzán (2020).

Sobre este respecto, el acuerdo de La Habana plantea un hito en sentar las bases de esa segunda emancipación que intentó hacer frente a las lógicas de un poder que buscaba la unidimensionalidad del conflicto, que lejos de las discusiones bizantinas sobre impunidad o ilegitimidad, o las más complejas como reforma rural y participación política consignadas en el texto de los acuerdos, se concentraban en otorgar voz a los sectores históricamente invisibilizados, desarrollando con esto un compromiso transmoderno ${ }^{11}$ que intenta desvincular la matriz informativa como potencia comunicativa del entretejido cultural, de la psique esquizofrénica del capitalismo colonizador. Determinando "para las organizaciones y movimientos sociales y populares no solo (...) el pleno ejercicio de derechos y libertades (...), sino también promover y facilitar los espacios para que transmiten sus demandas" (Oficina alto comisionado para la paz en Colombia, 2013, p. 3).

Son ese conjunto de subalternos, dispersos por el plano a partir de herencias coloniales que los han excluido de la representación (Castro-Gómez, 2015) política y por esto también, de la exposición mediática de sus demandas por considerarlas ajenas a la razón nacional y sustentada por los sectores privilegiados dueńos del epicentro de la comunicación social, los mismos que en los albores de la república clamaban por una única cultura nacional que desterrase, invisibilizara o eliminara las razas vulgares que entorpecían el desarrollo del país en su urgente camino a la modernidad, como afirmaban las tesis lebobianas bien recibidas por la alta cultura colombiana al expresar una sólida biopolítica racial. ${ }^{12}$

10. A raíz de una publicación del New York Times sobre el regreso de los "falsos positivos" a Colombia, el periodista Daniel Coronel descubre que la revista Semana, tal vez la más influyente del país y de donde era su principal columnista, había "engavetado" la información para no generarle mala prensa al Gobierno, por lo que decide escribir su columna del 26 de mayo de 2019 exponiendo tal situación. El resultado de la misma fue la cancelación de la columna y la decisión del medio de no contar más con los servicios del periodista.

11. La entendemos desde Dussel como la alternativa paradigmática a los planteamientos de la modernidad, la cual es una construcción básicamente europea que subordina las experiencias de la periferia a la hegemonía del centro. Por lo que la transmodernidad propone "culminar el inacabado e incompleto proyecto de la descolonización que se inició en América Latina en los años sesenta y setenta del siglo pasado a partir de discusiones sobre programas de educación bilingüe en Perú, Ecuador y Bolivia y la interculturalidad". (Vélez de la Calle y Córdoba, 2016, p. 1002)

12. Las ideas de Gustave Lebon las desarrolla de manera precisa Santiago Castro-Gómez (2009) en "tejidos oníricos". Allí establece una cartografía de la psicología colombiana a partir de su configuración de lo que llamó "la guerra de las razas" como base de las prácticas biopolíticas donde "el viejo imaginario colonial de la limpieza de sangre empezó a ser resemantizado en clave leboniana desde finales del siglo XIX con los nuevos discursos de la biología y de la medicina social. 
De ahí que se distribuyan matrices de interpretación que tienden a homogenizar y caricaturizar la estética del accionar fenoménico del narcotráfico, a banalizar las vidas o los acontecimientos durante el conflicto armado y a desdibujar la desigualdad para presentarla como una suerte de medio estereotipado donde priman la alegría y la espontaneidad de unas subjetividades aún ancladas en la minoría de edad, cuestión que reproduce la categorización racial de la conciencia de centro, que ve a los otros como depositarios de una herencia bárbara que desordena al país y acongoja a las pobres almas civilizadas que aún resisten en sus refugios citadinos.

Lo examinado, permite identificar algunos puntos de encuentro entre las matrices de verdad impuestas por la élite propietaria del medio que desarrolla toda una tipología del dominante-dominado y las resistencias emergentes en el acontecimiento de la comunicación, a partir de la revisión al horizonte del conflicto armado colombiano por parte de subjetividades subalternas que comienzan a agrupar y a demandar un espacio en la expresión comunicativa diversa desde la multiplicidad cultural e ideológica interviniente en la comprensión prismática y heterogénea de nuestro conflicto histórico.

\section{Hegemonía y medios de comunicación: apuntes críticos sobre la mediocracia}

Se examinan las condiciones de enunciación mediática que objetivan un punto de vista unilateral sobre la responsabilidad ideológica en la confrontación armada. Así, se interpreta el papel informativo como infinita repetición de contenidos hegemónicos, que categorizan una habilitación del pathos distancial nietzscheano como condición mediocrática de relaciones de poder, para definir y establecer esa sensación general y básica, duradera y dominante, de ser una especie superior que manda a otra especie inferior, a algo bajo, ese es el origen de la contraposición bueno y malo. (Nietzsche, 2016)

Si se revisa el comportamiento de los medios durante los diálogos del Caguán, se encontrará que no solamente se centraron en la fabricación de verdades, sino también en la invisibilización de actores, al tergiversar y minar la realidad que estaba presentándose para habilitar un estatuto nuevo del poder, que el analista norteamericano Danny Schechter (2001) atinó en denominar mediocracia, como "un sistema político atado al sistema mediático" (p. 6). En ese orden de ideas, se dedicaron a defender los intereses que tenía la razón gubernamental de ese entonces por encima de los sectores subalternos necesitados de visibilización. ${ }^{13}$

Podemos afirmar que la evolución del interés mediático por el conflicto armado tuvo tres escenarios en la historia reciente. El primero se deriva del proceso del Caguán que tenía una base de naturaleza dialogada. El segundo fue la reacción bélica del Gobierno de Álvaro Uribe (2002-2010) ante la pérdida de confianza con la insurgencia, y el tercero la firma de los acuerdos con la guerrilla de las FARC en La Habana. Aunque vale destacar

13. Un ejemplo de ello lo cuenta Raúl Trejos en el libro Poderes salvajes. Democracia sin contrapesos al respecto de un sonado caso de corrupción en México donde fue grabado un funcionario público recibiendo dineros de un empresario, si bien. "Televisa no grabó esos videos, pero hizo política con ellos. Al difundirlos sin explicar cómo los había obtenido y con la celada que le tendieron a Bejarano esa empresa perjudicaba a Andrés Manuel López Obrador, el Jefe de Gobierno de la Ciudad de México cuyas aspiraciones para competir dos años más tarde por la Presidencia de la República eran inocultables desde entonces. La imagen de honestidad que ese personaje había querido construirse, quedó maltratada con la exhibición de los discutibles comportamientos de algunos de sus colaboradores más cercanos. De esa manera se beneficiaban los intereses del presidente Vicente Fox y su esposa (en ese entonces aspirante, ella también, a gobernar el país) de esa manera también Televisa influía, consciente y eficazmente, en la lucha por el poder político en México" (Trejos, 2004, pp. 15, 16). Otro ejemplo muy similar del papel mediático en la estructura de la narrativa político ocurrió en Colombia con el sonado caso del llamado "Petrovideo" en que se observó al jefe de la oposición recibiendo unos dineros en la sala de un apartamento en Bogotá. Si bien se demostró que no existió nada ilegal, la narrativa mediática fue contundente para formar mantos de duda acerca de la honorabilidad del político. 
que fue el segundo escenario el que deja una huella más profunda en las prácticas políticas colombianas debido a que fortaleció el paramilitarismo, arreció militarmente las operaciones contrainsurgentes e incluyó al mundo político en un ágora esquizofrénica que acabó con la identidad partidista a partir de la reforma del 2003 que

(...) reconfiguró el sistema de partidos. Las nuevas reglas electorales prohibían la doble militancia, establecieron las listas únicas, el umbral electoral (...) y permitió por única vez que los congresistas se movieran de partido y se unieran para crear nuevos partidos. Con la reforma una parte de los movimientos internos de los partidos decidieron autonomizarse y se generó una dinámica de escisiones y agregaciones. Del Partido Liberal se separó Cambio Radical (que reagrupó a otros cuatro movimientos: Colombia Siempre, Voluntad Popular, Somos Colombia y Movimiento sin corrupción Colombia), también se separaron Alternativa de Avanzada Social, Por el País que Sońamos, Nuevo Liberalismo, Huella Ciudadana, El Movimiento Nacional Progresista, El Movimiento de Renovación y Acción Social-Moral, Colombia Viva, Apertura Liberal y Colombia Democrática. Por iniciativa de seguidores del presidente Álvaro Uribe Vélez se creó el Partido Social de la Unidad Nacional, el cual reunió congresistas retirados del Partido Liberal y algunos pequeńos partidos regionales, como Sí Colombia y Vamos Colombia, incluso dirigentes conservadores. Del Partido Conservador se separaron de forma definitiva Equipo Colombia, Movimiento Nacional, Movimiento de Integración Regional y Conservatismo Independiente. Algunos pocos movimientos se reincorporaron a este partido (Salvación Nacional, Nueva Fuerza Democrática, Fuerza Progresista, Progresismo Democrático y el Unionismo). (Duque, 2014, p. 325)

Toda esta corriente neopartidista que responde al interés por desatar un discurso frontal en contra del enemigo único y derrotarlo a como diera lugar, generó la estrategia político-militar del Gobierno de entonces nominada Seguridad democrática, concentrada "en acciones jurídicas, políticas y de opinión para desatar una ofensiva militar, política y judicial contra los denominados factores de violencia, que eran presentados como obstáculos que impedían el crecimiento económico y social del país" (Centro Nacional de Memoria Histórica, 2013, p. 179), asunto mayoritariamente inscrito en la matriz del pathos de la distancia.

Es importante resaltar cómo la figura presidencial de Álvaro Uribe Vélez significó la dinamización de los medios de comunicación para inflar su favoritismo (como lo deja ver Daniel Coronel) desde la difusión de un "estilo de gobierno particularmente autoritario y, esencialmente, en el proyecto político de ultraderecha” (revista Pueblos, 2008, p. 11.) que prometía acabar con "mano dura" la insurgencia en seis meses, en vista del fracaso presentado en los diálogos de paz que comandaba el expresidente Andrés Pastrana Arango (1998-2002) con las guerrillas de las Farc-EP.

Adicionalmente, se dedicaron esfuerzos gubernamentales, empresariales y mediáticos a hacerle apología al Plan Colombia, optando estratégicamente por vender la idea de que aparecía como una necesidad para el país, por lo que se hacía urgente su aprobación para apoyar la guerra contra las drogas y contribuir a la construcción de paz. Cuestión que derivaría en la agudización del conflicto social, como lo expresa el Centro Nacional de Memoria Histórica (2013):

Las presiones y los incentivos por resultados a la fuerza pública tuvieron consecuencias perversas, pues desencadenaron comportamientos criminales, como los "falsos positivos", casos frente a los cuales la Fiscalía llevaba, al 31 de mayo del 2011, 1.486 investigaciones, con 2.701 víctimas. Dentro de los costos de la estrategia de seguridad se destacaron, además, el hostigamiento y la persecución judicial contra las organizaciones políticas y sociales opuestas al gobierno, hecho que desató el escándalo de las interceptaciones telefónicas y los seguimientos ilegales del DAS a dirigentes políticos, periodistas, magistrados y congresistas. (p. 178) 
Una vez consolidada la presidencia de Uribe Vélez y para garantizar la seguridad a los inversionistas extranjeros, diseńó su política a partir del maridaje con los medios de masas. Más importante que ganarle la guerra a las Farc-EP, lo esencial consistía en mostrar la sensación de que la estaba ganando. Así, los medios se convirtieron en una caja de resonancia para transmitir los fragmentos de la guerra que permitieran consolidar posiciones específicas de sujeto al servicio de esta cultura de seguridad. ${ }^{14}$ Cuestión que se demuestra en la Gráfica 1:

\section{Gráfica 1}

Desempeño de Álvaro Uribe como presidente

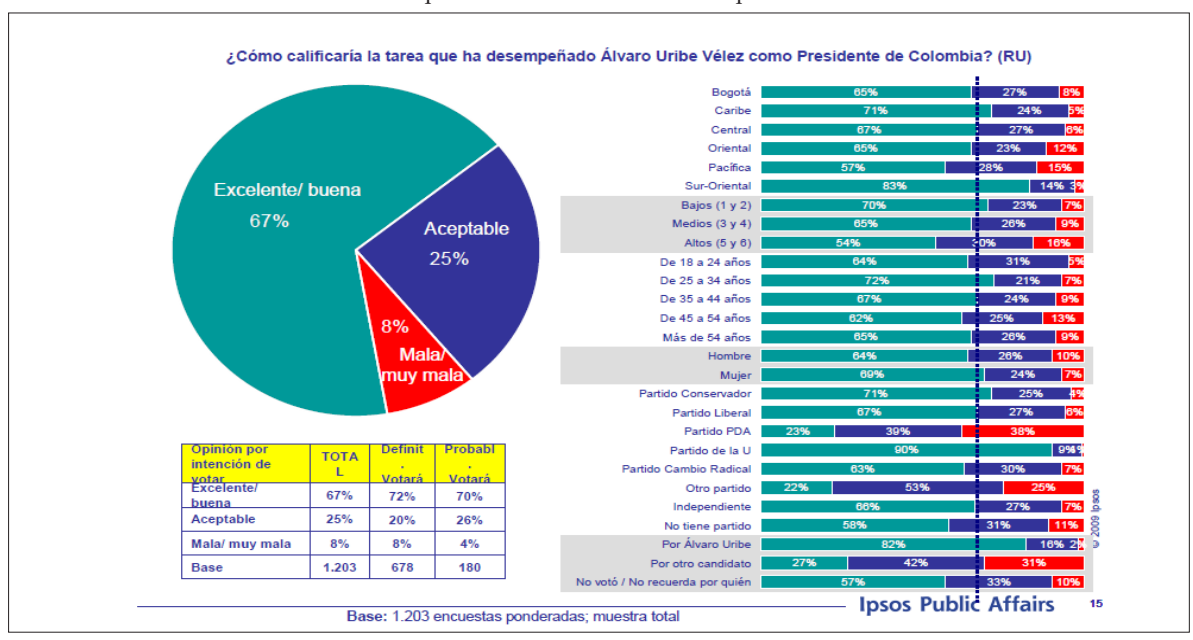

Fuente: Ipsos-Napoleón Franco, 2009.

Así también, los medios se encargaron de legitimar ante la opinión pública la connotación gobiernista que transmutaba nominal y jurídicamente el carácter de paramilitar al de integrante de banda criminal (Bacrim), desestimando así la naturaleza ideológica de las alianzas probadas entre Estado, empresariado y grupos paramilitares

(...) que resultaron efectivas para la promoción del latifundio ganadero, la agroindustria, la minería y los megaproyectos, en detrimento de la economía campesina. Uno de los casos emblemáticos de apuntalamiento de este tipo de desarrollo lo ofrece la alta concentración geográfica del cultivo de palma africana sobre el corredor estratégico y la zona de retaguardia de las AUC. De acuerdo con el informe de desarrollo humano, Colombia rural. Razones para la esperanza, las 360537 hectáreas de palma africana que existen en Colombia hoy en día se concentran en el Magdalena, Norte de Santander, Magdalena medio, sur de Bolívar, sur de Cesar, Montes de María, bajo Atrato, Llanos Orientales, piedemonte casanareño y andén Pacífico. (Centro Nacional de Memoria Histórica, 2013, p. 177)

Tales alianzas surgen no a partir de un azar exterior, sino que dependían de condiciones de existencia que se fueron históricamente configurando para que la conciencia nacional pasara de la matriz de la paz al enfoque de la belicosidad gubernamental. De ahí la impor-

14. Las estrategias que caían del poder gubernamental para combatir "el mal mayor", significaba la apertura de narrativas, muchas veces contrahistóricas, que desestimaran la existencia de un conflicto. Tal organización discursiva "tomaba ribetes de guerra patria, pues el rol de la población civil en la lucha contra el terrorismo fue señalado por el presidente Âlvaro Uribe en los siguientes términos, en el año 2003: "Los colombianos no cederemos ante esa amenaza. La vamos a derrotar con la colaboración de la ciudadanía. El concepto clave aquí es solidaridad. Solidaridad entre los ciudadanos y solidaridad con la fuerza pública”. Esta política contó con un amplio respaldo de la opinión pública y la clase política y empresarial, cuyo consenso partía del supuesto de que era necesaria una política de Estado y de Gobierno de largo aliento para derrotar a la guerrilla. El enorme esfuerzo militar en que incurrió el Estado para conducir su ofensiva lo llevó a pasar de un pie de fuerza de 215.000 hombres en 1998 a 445.000 en 2010". (Centro Nacional de Memoria Histórica, 2013, p. 179) 
tancia de analizar las repercusiones fracasadas del Caguán y la llegada de una cultura de seguridad que orientó a la opinión pública a percibir "cómo el conflicto armado agravaba la crisis económica y ello acabó por incidir en su radicalización política y su viraje hacia una solución militar de la guerra”. (Centro Nacional de Memoria Histórica, 2013, p. 178)

En consecuencia, la resonancia máxima de ese viraje cardinal fue el ocurrido en la refrendación de los acuerdos de La Habana, en el que los actores políticos contradictorios a la paz con las Farc desataron todo tipo de corrientes discursivas reproducidas por las grandes empresas mediáticas, pues aprovechando un clima social que no se fiaba del diálogo y apelaba a las iniciativas de mano firme, retumbó en la victoria del $n o^{15}$ el dos de octubre de 2016.

Precisamente, la investigación a cargo de la Misión de Observación Electoral, denominada Medios de comunicación y plebiscito de refrendación de los acuerdos de paz, a partir de una medición cualitativa y cuantitativa de la información producida por diversos medios (prensa-digital e impresa, radio y televisión), observa la posición tan marcada de los principales canales informativos del país al citar reiteradamente fuentes a favor del no, tal como se presenta en la Gráfica 2.

Gráfica 2

Posiciones reflejadas en los medios de comunicación

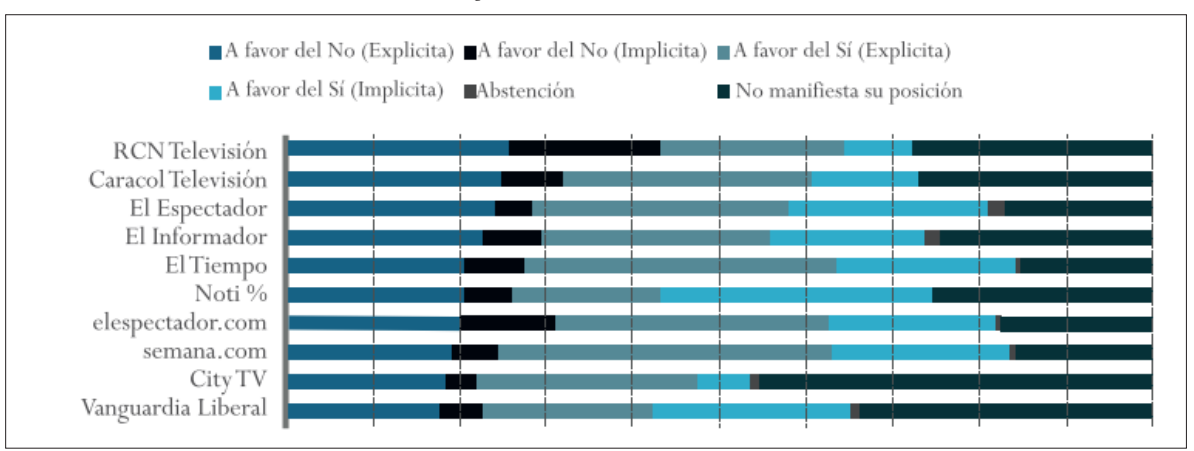

Fuente: datos y estadísticas MOE

Esto demuestra, si no directamente una anexión ideológica comprometida, al menos el interés por promover una sola idea, quebrantando así el principio de objetividad que ostenta como posibilitador de una opinión pública libre y decidida. Así, el papel político desempeñado por los principales medios masivos de comunicación del país al momento de incidir en el plebiscito, resulta determinante para su fracaso, debido a que haciendo uso del investimento mediocrático "los conductores actúan como fiscales, los noticieros se vuelven tribunales, la justicia se allana a los medios y el veredicto mediático es irrecusable" (Trejo, 2004, p. 15), cuestión muy similar a la que ocurre con el caso del líder insurgente Jesús Santrich ${ }^{16}$ y su proceso, en su mayoría mediático, de los vínculos con el narcotráfico luego de la firma de los acuerdos.

15. El dos de octubre de 2016, el presidente de la república Juan Manuel Santos consultó al pueblo colombiano sobre si refrendar o no los acuerdos entre el Estado y la guerrilla de las Farc-EP a partir de la pregunta: ¿Apoya usted el acuerdo final para la terminación del conflicto y la construcción de una paz estable y duradera? Resultando lo siguiente: $49,76 \%$ para el sí y $50,23 \%$ para el no.

16. El 9 de abril de 2018 fue detenido por la fiscalía Seuxis Paucis Hernández Solarte más conocido como Jesus Santrich, integrante del partido político Fuerza alternativa revolucionaria del común, antes guerrilla de las FARCEP, acusado de participar en delitos de narcotráfico hacia Estados Unidos luego de la firma de los acuerdos de paz. El caso ha generado conmoción, debido a la fuerte polarización, en su mayoría librada en territorio mediático sobre los mecanismos, intensiones e implicaciones de su captura para con la estabilidad y credibilidad del proceso en el marco del posacuerdo. 
De esta manera, se crea una matriz de verdad que condena todo aquello que rompa los parámetros de la tranquilidad nacional. Por esto, las luchas indígenas, obreras, campesinas y estudiantiles serán apaciguadas por los diferentes aparatos ideológicos y de represión estatal diseñadas para evitar su resonancia social y cultural, cuestión que nos recuerda el modelo racial que prima en la psique cultural colombiana. Así lo cuenta algún protagonista en los talleres del CNMH, al respecto del fenómeno paramilitar:

No, [los paramilitares llegaron] por la presencia de la guerrilla, porque esos son enemigos acérrimos, (...) pero no acabaron con la guerrilla sino [que] acabaron con la población civil. A la guerrilla no le hicieron ni un tiro (...). Ellos decían que como todos los civiles éramos guerrilleros, entonces ellos querían acabar era con los civiles (CNMH, taller de memoria, San Calixto, 2016). (Centro Nacional de Memoria Histórica, 2018, p. 315)

Estigmatizar la protesta social y ocultar a los colombianos las razones que obligan a los diferentes sectores sociales y populares a acudir a las vías de hecho para hacerse escuchar frente al abandono y exclusión estatal a la cual han sido sometidos históricamente, es un ejercicio recurrente del medio masivo de comunicación. En las portadas de los periódicos, en las noticias centrales de sus noticieros o en sus programas de opinión, exacerban el relacionamiento de las demandas ciudadanas como ligadas al "terrorismo", estableciendo así una interpretación homogénea que endilga a los actores de la demanda todo suerte de accionares para debilitar el funcionamiento económico del país.

Reducido mediáticamente el valor de la demanda social a vandalismo acrítico, producto de almas envenenadas por el resentimiento social y el atraso cultural, se crea una matriz de conocimiento que busca generar la temperatura ideal para que la opinión pública manifieste su rechazo o al menos su indiferencia a las corrientes ideológicas de la inconformidad materializada en la protesta social.

Precisamente, este es el epicentro de las luchas estudiantiles, campesinas, indígenas, las negritudes y todas aquellas que representan coordenadas diferenciales, negadas de toda participación pública por las dinámicas de corrección de una sociedad civil que no "parece entenderse hoy fuera de las condiciones globales, económicas y tecnológicas" (CastroGómez y Mendieta, 1998, p. 71). Es sobre este aspecto que la comunicación auténtica como acto de creación, desprovista del investimento esquizofrénico del capitalismo cultural, pueda despertar una pluralidad de demandas que sean articuladas en una cadena equivalencial para ubicar al pueblo como base antagónica para resistir con firmeza las estructuras del poder dominante, pues son estos quienes padecen toda la contundencia de la violencia, la indiferencia y la manipulación mediocratica, debido a que:

(...) en la democracia, la justicia la imparten los jueces y los tribunales; en la mediocracia, son los medios los que absuelve y condenan. En la democracia, los medios dicen lo que los ciudadanos piensan; en la mediocracia, los ciudadanos dicen lo que los medios piensan. En la democracia, los líderes van a las comunidades, en la mediocracia, van a los programas de opinión. Para la democracia, los individuos son ciudadanos; para la mediocracia son audiencias. En la democracia la información es una cosa, la opinión es otra y la propaganda es otra; en la mediocracia no hay fronteras (manipulación y controles globales). (Antillano en Britto García, 2005, p. 300)

Frente a este fenómeno, es indispensable el levantamiento y la legitimación de las demandas populares que funjan como antagonistas efectivos para movilizar acciones democráticas que sustraigan el imperar mediocrático como altavoz de la cultura política y jurídica dominante en Colombia, buscando en las dinámicas subalternas el cuerpo dialógico y democrático que haga de la comunicación un campo de extralimitación que radicalice las apariciones de sectores populares no representados en la perspectiva pública de lo hegemónico-mediático. 


\section{Apuntes finales}

Durante este recorrido hemos confirmado la hipótesis de partida, puesto que se ha evidenciado que en Colombia la mediocracia configuró procesos de comunicación política en que los sistemas político y comunicativo se aseguraron las condiciones de autolegitimación y autorreproducción. Esto nos porta a demandar espacios de reflexión para descubrir la configuración del medio de comunicación de masas como actor político cercano al capitalismo cultural, para abrir el debate sobre si es legítimo que empresas privadas con fines de lucro manejen los flujos informativos. Por tanto, esta caracterización sugiere la atención inmediata por multiplicar las veedurías y la aparición de mediaciones alternativas que no pertenezcan a esta naturaleza especifica de poder.

En un cruce en el que confluyen democracia, espacio público y medios de comunicación, hemos ubicado el proceso comunicativo auténtico como el epicentro del antagonismo que, lejos de toda actitud o intensión homogenizante, polarice los diálogos democráticos entre la sociedad política y la sociedad civil. En tal sentido, se trata de hallar en la multiplicidad el estatuto de la democracia que ha redundado en la metafísica de lo uno al acotar el pluralismo a la expresión simple de la petición, toda vez que es una suerte de mecanismo del conservadurismo jurídico que condena el conflicto al ocultamiento y por tanto, a la imposibilidad de abierta comunicación, que como demuestra el libro fundante sobre la historia de la violencia en Colombia de Guzmán, Fals Borda y Umaña (1988), el diálogo sobre la violencia como categoría material permite "crear soluciones; crear en este caso es persistir en la solución. Gran dosis de la discontinuidad, la momentaneidad y la transitoriedad de las medidas del tratamiento aplicado obedece a la omisión del diálogo entre todos los representantes de los distintos sectores colombianos”. (p. 419)

Pensamos así, que la identidad comunicativa debe movilizarse como plataforma expresiva del conjunto cultural, asegurando con ello la participación como visibilidad de los mundos de vida en la estructura de las esferas públicas, cultural y política, hoy dominadas por las estratagemas del liberalismo burgués.

Para avanzar en lo anteriormente expuesto, es indispensable que la sociedad esté preparada para afrontar la estructuración de la experiencia individual y una reformulación a gran escala, de la acción "con los otros" (la identidad social), con la finalidad de aspirar a que el país se comprometa en la construcción de una ley de medios plural, para enfrentar la mediocracia que históricamente ha constreñido la información de acuerdo con intereses del particularismo económico. "Por consiguiente, se trata de elaborar alternativas posibles y seleccionar la opción deseada. El desarrollo no se guía por soluciones objetivas. Por tanto, hay que elaborar y decidir continuamente los objetivos de la sociedad. Eso es hacer política" (Martín-Barbero, 2010, p. 243). Así, la emergencia de la comunicación popular tiene que ampliarse más allá de las responsabilidades comunitarias, de las organizaciones sociales y populares e integrar las discusiones de la academia y el accionar estatal para producir otra experiencia cultural que señale "la percepción de dimensiones inéditas del conflicto social, la formación de nuevos sujetos-regionales, religiosos, sexuales, generacionales y formas nuevas de rebeldía y resistencia. (Martín-Barbero, 2010, p. 243)

En consecuencia, este trabajo hizo acercamientos importantes sobre el papel del medio de comunicación respecto a la interpretación de las esferas política, cultural y social, posibilitando con ello una fenomenología que derivó en la determinación de un logos mediocrático como factor colonizador que sigue perpetuando la brecha entre el centro y las periferias. Por esto, es determinante que los proyectos futuros en comunicación estén articulados a rescatar las voces subalternas que componen el réquiem de nuestro conflicto histórico para articular las demandas a la exigencia de derechos para, como afirmaba 
Dussel (2006), irradiar formas de vida política que aseguren la liberación, alteridad y solidaridad como base de una segunda emancipación.

\section{Referencias}

Adorno, T., Horkheimer, M. (1988). Dialéctica del Iluminismo. Buenos Aires: Editorial Sudamericana.

Barroco, M. (2004). Ética y Servicio Social: fundamentos ontológicos. Sao Paulo, Brasil: Cortéz Editora.

Britto, L. (2005), "Investigación de unos medios por encima de toda sospecha". La Habana: Fondo Editorial Casa de las Américas.

Cárdenas, J. (2015). Los medios de comunicación como actores (des) legitimadores. Algunas reflexiones acerca del rol de los medios de comunicación sobre la construcción de la opinión pública en torno al proceso de paz de la habana. Análisis politico, 28(85), p. 38-56. https:// doi.org/10.15446/anpol.v28n85.56245

Castro-Gómez, S. y Mendieta, E. (1998). Fragmentos globales: latinoamericanismo de segundo orden. En Teorías sin disciplinas. Latinoamericanismo, poscolonialidad y globalización del debate. Editorial Porrua: México.

Castro-Gómez, S y Grosfoguel, R. (2007). El giro decolonial: reflexiones para una diversidad epistémica más allá del capitalismo global. Bogotá: Siglo del Hombre Editores; Universidad Central, Instituto de Estudios Sociales Contemporáneos y Pontificia Universidad Javeriana, Instituto Pensar.

Castro-Gómez, S. (2009) Tejidos Oniricos. Bogotá: Editorial Pontificia Universidad Javeriana.

Castro-Gómez, S. (2015). Revoluciones sin sujeto. Ciudad de México: Editorial AKAL.

Centro Nacional de Memoria Histórica (2018), Catatumbo: memorias de vida y dignidad, $\mathrm{CNMH}$, Bogotá

Centro Nacional de Memoria Histórica (2013). ;Basta ya! Colombia: Memorias de guerra y dignidad. Bogotá: Imprenta Nacional.

Córdoba, M. E. \& Vélez-De La Calle, C. (2016). La alteridad desde la perspectivade la transmodernidad de Enrique Dussel. Revista Latinoamericana de Ciencias Sociales, Niñez y Juventud, 14 (2), pp. 1001-1015.

De Sousa, B. (2003) Critica de la razón indolente. Bilbao: Editorial Desclée de Brower

Deleuze, G. (2012). ¿Qué es el acto de creación? Revista Fermentario, (6). 1-16. Recuperado de: http://fermentario.fhuce.edu.uy/index.php/fermentario/article/view/110

Deleuze, G y Guattari, F. (2015) ¿Qué es la filosofía? Barcelona: Editorial Anagrama.

Duzán, M. (2020). El periodismo debe ser incomodo a todos los poderes. Recuperado de. https://www.semana.com/nacion/multimedia/para-que-escribir-maria-jimena-duzan-habladel-periodismo-hoy/696724/.

Dussel, E. (1996) Filosofía de la liberación. Bogotá: Editorial Nueva América. ulo

Dussel, E. (2006). 20 tesis de politica. Madrid: Siglo XXI editores.

Duque, J. (2014).Partidos y partidismo. Los partidos políticos colombianos y su enraizamiento en la sociedad. Revista facultad de derecho y ciencias politicas. 44 (120), pp. 311-347

Falsos Positivos-New York Times. Disponible en: https://www.youtube.com/watch?v=hpNZ2ot Qn2Y\&pbjreload=10 [27 de mayo de 2019]

Foucault, M. (2013) La arqueología del saber. México: Siglo XXI editores.

García, A. (2013). Dialéctica de la Democracia. Bogotá: Ediciones Desde Abajo. 
Geertz, C. (2003). La interpretación de las culturas. Barcelona: Editorial Gedisa

Guzmán, G; Fals Borda, O y Umańa, E. (1988). La violencia en Colombia tomo II. Bogotá: Editorial Printer.

Heidegger, M. (2009). Ser y tiempo. (J.E. Rivera, Trad,). Madrid: Trotta.

Lazarsfeld, P. F. y Merton, R. K. (1985). "Comunicación de masas, gustos populares y acción social organizada”, en M. de Moragas (ed.): Sociología de la comunicación de masas II. Estructura, funciones y efectos. Barcelona: Gustavo Gili, pp. 22-49

Lipovetsky, G. (2007). La Felicidad Paradójica. Barcelona: Editorial Anagrama.

Martín-Barbero, J. (2010). De los medios a las mediaciones. Comunicación, cultura y hegemonía. México: Ediciones GG.

Martín-Serrano, M. (1993). La producción social de comunicación. Madrid: Alianza Editorial.

Márquez-Fernández (2018). Democracia sub-alterna y Estado hegemónico. Crítica politica desde América Latina. Buenos Aíres: Editorial Aleph.

Nietzsche, F. (2016). Obras completas: volumen III. Madrid: Editorial Tecnos

Narváez, A. (2013). Educación y Comunicación: del capitalismo informacional al capitalismo cultural. Bogotá: Editorial Universidad Pedagógica Nacional.

Oficina alto comisionado para la paz en Colombia. (2013). La discusión del punto 2 Participación Política: Apertura Democrática para Construir la Paz. Recuperado de: https://www.jep.gov.co/ Sala-de-Prensa/Documents/tomo-3-proceso-paz-farc-participacion-politica.pdf.

Pardo, J. (2014). A propósito de Deleuze. Valencia: Editorial Pre-textos.

Pineda, A (2001). El modelo de propaganda de Noam Chomsky: medios mainstream y control del pensamiento. Ámbitos, (6).

Ramírez, A. (2016). Rafael Correa, sobre libertad de prensa. (Video online) disponible en https:// www.youtube.com/watch?v=s10_BJz-m74

Rafael Correa sobre el poder de los medios de comunicación (Honoris Causa UNQ). Alex Kicillof. Disponible en: https://www.youtube.com/watch?v=XMuzLue5YS8 [20 de mayo de 2017].

Remsseler (2005). En Britto, L. Investigación de unos medios por encima de toda sospecha. La Habana: Fondo Editorial Casa de las Américas.

Reig R. (2017). "Metodología para el estudio de la estudio de la estructura mundial de la información”. En: R. Reig y A. Lobo (Eds.) El laberinto mundial de la información, Barcelona: Anthropos: pp. 15-33.

Revista Pueblos (2008). Recuperado de: http://www.revistapueblos.org/old/spip.php?article729

Schechter, D. (2001) "Americas's Shining Mediaocracy". Hail to the Thief. How the Media Stole the U.S. Presidential Election. The MediaChannel.org, Nueva York.

Trejo, R. (2004). Poderes salvajes, Mediocracia sin contrapesos. México: Ediciones Cal y Arena.

Vásquez, J. (2017). El ruido de las cosas al caer. Bogotá: Editorial Alfaguara.

Valencia, J. (2012). Mediaciones, comunicación y colonialidad: encuentros y desencuentros de los estudios culturales y la comunicación en Latinoamérica. Revista Signo y Pensamiento, volumen XXX, pp. 156-165. 